Revista Complutense de Educación

ISSNe: 1988-2793

http://dx.doi.org/10.5209/RCED.53881

\title{
La educación mediática en la universidad española
}

Autores: Joan Ferrés y Maria-Jose Masanet

Editorial: Gedisa

Año de publicación: 2015

$N^{a}$ de páginas: 153

ISBN: 978-84-16572-10-6

Desde hace más de 30 años, importantes organismos mundiales insisten en la urgencia de formar ciudadanos competentes mediáticamente. Es una demanda que crece con el peso cada vez mayor de los medios de comunicación en nuestras vidas. Este libro presenta los resultados de un estudio desarrollado por 19 investigadores adscritos al proyecto $\mathrm{I}+\mathrm{D}+\mathrm{i}$ sobre competencias en comunicación audiovisual en el entorno digital, financiado por el Ministerio de Ciencia e Innovación. El punto de partida fue explorar la presencia de la educación mediática ofrecida en los grados universitarios de educación y comunicación de toda España, así como comprobar el peso que se dan a las competencias audiovisuales, las emociones o el inconsciente en la educación superior. La obra se organiza en ocho capítulos, cada uno de los cuales aborda aristas específicas que van desde la revisión curricular y las prácticas docentes, hasta el análisis puntual de las dimensiones de la educación mediática presentes en ellos.

El primer capítulo actualiza discusiones teóricas relevantes en torno a la educación mediática — que abarca medios "masivos" y los así llamados "sociales"_-, partiendo de la ambigüedad conceptual que genera la coexistencia de términos diversos tales como "alfabetización digital" o "transliteracy" que, con matices, se ocupan de lo mismo. Así también, enfatiza en la importancia de la comunicación persuasiva, pues considera que "la educación mediática ha de garantizar tanto la capacidad de producir mensajes educativos eficaces mediante el conocimiento y la gestión de las emociones de los interlocutores, como la de comprender y gestionar los efectos educativos o deseducativos que los mensajes mediáticos producen en uno mismo incidiendo en nuestro cerebro emocional" (p. 25). A propósito, una de las conclusiones del capítulo cuarto, centrado en la dimensión de la recepción e interacción mediáticas a nivel universitario, es que "las instituciones educativas, concentradas en el qué enseñar, han olvidado el cómo comunicar, lo que ha producido importantes brechas 'culturales' entre alumnos y docentes”. (p. 76)

Los capítulos dedicados a la formación de docentes concluyen que la incorporación de materias de educación mediática es bastante reciente y se encuadra históricamente dentro de lo que se denomina "Tecnología Educativa". No es extraño, por lo tanto, que priorice una aproximación instrumental, vinculada al uso de los medios como auxiliares didáctico para la enseñanza, o que prefiera la dimensión tecnológica a otras, como la estética. Como señala el capítulo tres, la formación en medios de la mayoría de docentes en esta materia ha sido sobre todo autodidacta y se ha limitado a la lectura crítica y a la producción en plataformas digitales, lo que impide apreciar mayor innovación en cuanto a didáctica o metodología. Esto se sustenta en parte en el desprecio académico del uso social de los medios y las prácticas culturales 
que producen, privilegiando más bien una mirada del dispositivo tecnológico como transmisor de conocimientos, en lugar de productor de significados o interacciones. El reto, dicen los autores, está en innovar trascendiendo el texto escrito e integrando, por ejemplo, narraciones audiovisuales, formatos digitales o redes sociales, más cercanos al interés del estudiante, sea para el análisis crítico de sus contenidos, la producción transmedia o la evaluación de sus aprendizajes.

Respecto a la formación de comunicadores, el estudio acusa una "tensión instrumental y reductora de la especialización" (p. 104), a partir del debate entre la necesidad de educar a un comunicador crítico y libre - en clave freiriana - $\mathrm{u}$ otro más funcional a la sociedad de consumo. Aún cuando el discurso dominante apuesta por lo primero, resulta difícil traducirlo en concreto: "se observan discrepancias epistemológicas sobre la finalidad y alcance de la educomunicación que se traduce en una discusión sobre la necesidad de establecer asignaturas concretas o apostar por una transversalidad de la materia" (p. 114). Luego de analizar los planes de estudio, se advierte una presencia marginal de asignaturas directa o indirectamente relacionadas con la educación mediática. Además, una tendencia a vincularla más a la especialidad de Comunicación Audiovisual que a la de Publicidad o Periodismo. Asimismo, en relación a cómo se aborda la ética -inherente a la educación mediática - , queda clara que persiste la mirada pasiva que prefiere la observancia de normas de conducta impuestas a la reflexión constante sobre el ejercicio de la profesión. Esto es consecuencia, según los investigadores, del proceso de convergencia europea de los grados, que auspicia una formación menos generalista en beneficio de saberes más específicos (o parcelados y desconectados, añadiríamos).

El libro precisa algunas carencias y limitaciones con que se abordan estas competencias en la universidadespañola. Entre ellas estáreducir laeducaciónmediática a lo racional, en desmedro de lo emocional; a lo informativo, sin considerar que el entretenimiento es parte central de la cultura digital; y a lo consciente, sin ocuparse del inconsciente, que es donde se producen las operaciones ejecutivas más potentes del ser humano. Al respecto, los editores consideran que existe un aproximación anacrónica y que "la educación mediática sólo puede justificar su presencia en el mundo académico si es capaz de ir revisando y actualizando sus postulados a la luz de los sucesivos descubrimientos de la ciencia" (p. 137). En esta línea, lamentan el desinterés por incorporar hallazgos recientes de la neurociencia que, en la última década, han dado un giro a la comprensión del problema educomunicativo y de los procesos de enseñanza-aprendizaje en general.

Del mismo modo, el texto cuestiona que la formación del espíritu crítico frente a los medios - presente casi siempre en el discurso de los docentes y los planes de estudiose limite a lo ideológico, desatendiendo otras dimensiones igualmente valiosas y atendibles, como la estética o la de las interacciones. Señalan Ferres y Masanet que "es una grave carencia reducir la educación mediática a la crítica de productos mediáticos, porque se pierde una oportunidad excepcional de comprendernos como personas, asumiendo nuestra complejidad y nuestras contradicciones" (p. 151).

Este libro constituye un diagnóstico y un llamado de atención, pero sobre todo una provocación para el desarrollo de proyectos que incidan en la formación mediática en el ámbito universitario, donde existe una deuda notoria.

Julio César Mateus Universidad Pompeu Fabra julio.mateus@upf.edu 